\title{
DETECTION OF AMPC BETA LACTAMASES IN CEFOXITIN-RESISTANT GRAM-NEGATIVE CLINICAL ISOLATES USING PHENYLBORONIC ACID
}

\author{
Mohammed Hisham Poilil Puthanpura1, Shabina Methele Pangat Balakrishnan², Rema Devi Santhakumari ${ }^{3}$, Beena Philomina Jose ${ }^{4}$, \\ Anitha Puduvail Moorkoth 5
}

\author{
${ }_{1}^{1}$ Assistant Professor, Department of Microbiology, Kannur Medical College, Kannur. \\ ${ }^{2}$ Assistant Professor, Department of Microbiology, Government Medical College, Kozhikode. \\ ${ }_{3}^{3}$ Professor and HOD, Department of Microbiology, Somervell Memorial CSI Medical College, Karakonam, Thiruvananthapuram. \\ ${ }^{4}$ Professor and HOD, Department of Microbiology, Government Medical College, Kozhikode. \\ ${ }_{5}^{5}$ Associate Professor, Department of Microbiology, Government Medical College, Kozhikode.
}

\begin{abstract}
BACKGROUND
AmpC $\beta$-lactamases are Ambler class $C$ enzymes that confer resistance to extended spectrum cephalosporins and are not inhibited by $\beta$-lactamase inhibitors. These enzyme-producing organisms produce infections that are associated with significant morbidity and mortality. Resistance to third-generation cephalosporins develop in these organisms after exposure to these agents. This complicates treatment options and carbapenems are considered optimal.
\end{abstract}

ABSTRACT

\section{MATERIALS AND METHODS}

In this cross-sectional study, AmpC $\beta$-lactamase production was determined in Gram-negative clinical isolates from various clinical samples. Isolates resistant to cefoxitin and third generation cephalosporin (3GC) antibiotics were tested for the production of AmpC $\beta$-lactamases by using an inhibitor-based method (IBM) with phenylboronic acid.

\section{RESULTS}

It was observed that, among the 100 Gram-negative isolates, 48 (48\%) were resistant to cefoxitin. Using IBM, the occurrence of AmpC $\beta$-lactamases was found in 24 (24\%) of these 48 isolates. ESBL/AmpC co-carriage was found in 13 (13\%) of these isolates by E-Test. Among the 24 AmpC positive isolates, 10 (41.6\%) were E. coli, 5 (20.8\%) were Enterobacter cloacae, 5 (20.8\%) were Klebsiella pneumoniae, 2 (8.3\%) were Acinetobacter baumannii and 2 (8.3\%) were Pseudomonas aeruginosa.

\section{CONCLUSION}

AmpC production can be determined in routine clinical microbiology laboratory using IBM as it is a simple, rapid and technically easy procedure. Thus, their accurate detection and characterisation plays an important role in their epidemiological survey, infection control and treatment.

\section{KEYWORDS}

Gram-negative Bacteria, AmpC $\beta$-Lactamase, Phenylboronic Acid, Cefepime.

HOW TO CITE THIS ARTICLE: Puthanpura MHP, Balakrishnan SMP, Santhakumari RD, et al. Detection of AMPC beta lactamases in cefoxitin-resistant Gram-negative clinical isolates using phenylboronic acid. J. Evolution Med. Dent. Sci. 2018;7(03):310-314, DOI: $10.14260 /$ jemds/2018/69

\section{BACKGROUND}

Production of $\beta$-lactamases by Gram-negative bacteria is the predominant mechanism for their resistance to $\beta$-lactam antibiotics. ESBLs and AmpC $\beta$-lactamases are the most commonly produced. ${ }^{1}$ They have become a major cause of hospital-acquired infection, particularly in the intensive care unit (ICU). Such bacteria are associated with severe infections such as bacteraemia, intra-abdominal infection, urinary tract infections and respiratory tract infections. AmpC $\beta$ lactamases are mostly chromosomally mediated cephalosporinases produced by Gram-negative bacteria that make them resistant to a wide range of beta lactam drugs thereby leading to serious problem in therapy.

'Financial or Other Competing Interest': None.

Submission 05-12-2017, Peer Review 29-12-2017,

Acceptance 04-01-2018, Published 13-01-2018.

Corresponding Author:

Shabina Methele Pangat Balakrishnan,

Assistant Professor,

Department of Microbiology,

Government Medical College,

Kozhikode.

E-mail: shabina_mb@rediffmail.com

DOI: $10.14260 /$ jemds $/ 2018 / 69$

\section{(c) $(1)$}

In the Ambler structural classification of $\beta$-lactamases, AmpC enzymes belong to class $C$, while in the functional classification scheme of Bush et $\mathrm{al}^{2}$ they belong to group 1 . Their clinical importance lies in they being resistant to both narrow and broad spectrum cephalosporins, $\beta$-lactam $/ \beta$ lactamase inhibitor combinations and aztreonam. ${ }^{3}$ The lack of inhibition by cephamycins and $\beta$ lactam/ $\beta$-lactamase inhibitor combination helps in differentiation between AmpC $\beta$-lactamase producer and ESBL producers. They are usually sensitive to the carbapenems and $4^{\text {th }}$ generation cephalosporins.

There are two types of AmpC $\beta$-lactamases chromosomal and plasmid-mediated. They have been found around the world in nosocomial and non-nosocomial isolates. AmpC production in Gram-negative bacilli is normally repressed. AmpC $\beta$-lactamase production returns to low levels after antibiotic exposure is discontinued, unless spontaneous mutations occur in the AmpD locus of the gene, leading to permanent hyperproduction (derepression). Chromosomal AmpC enzymes are seen in Citrobacter freundii, Enterobacter cloacae, Morganella morganii, Serratia marcescens and are inducible by antibiotics like cefoxitin and imipenem. The plasmid mediated AmpC $\beta$-lactamases are 
derived from chromosomally encoded genes and hydrolyse all $\beta$-lactam antibiotics except cefepime and carbapenems.

They are seen in Escherichia coli, Klebsiella pneumoniae and Proteus mirabilis. Unlike chromosome-mediated AmpC, plasmid-encoded AmpC enzymes are almost always expressed constitutively. 4 Detection of an AmpC $\beta$-lactamase in Klebsiella spp,, Citrobacter koseri or Proteus mirabilis is confirmatory for plasmid-mediated AmpC production because these organisms lack a chromosomal AmpC $\beta$ lactamases. 5

AmpC enzyme producing Gram-negative bacteria are isolated from hospitalised patients who have been exposed to $\beta$-lactam antibiotics. Cefepime is an effective drug in treating infections due to AmpC producers. It is a poor inducer of AmpC, penetrates through the outer cell membrane of bacteria and is little hydrolysed by the enzyme. Detection of AmpC production in Gram-negative clinical isolates helps to improve the clinical management of patients suffering from these infections. At present, there are no CLSI guidelines for detection of AmpC-mediated resistance in Gram-negative bacteria. A problem in therapy can arise due to misleading results, in phenotypic tests. Cefoxitin resistance is suggestive of AmpC production, but it is not specific as resistance to cefoxitin can also be mediated by certain class $A$ lactamases, carbapenemases and decreased production of outer membrane porins. ${ }^{6}$ Boronic acid (BA) derivatives have been considered to be reversible inhibitors of AmpC enzymes. ${ }^{7}$ Many studies have validated the use of BA to detect AmpC $\beta$-lactamases among Gram-negative bacteria.8,9

\section{Aim of the Study}

To detect the production of AmpC enzymes in Gram-negative clinical isolates resistant to cefoxitin and third generation cephalosporin (3GC) by inhibitor-based method using boronic acid.

\section{MATERIALS AND METHODS}

\section{Study Setting}

The study was conducted in the Department of Microbiology, Government Medical College, Kozhikode, during March 2011February 2012 for a period of one year.

\section{Study Design}

Cross-sectional study.

\section{Study Group}

Patients admitted in Govt. Medical College, Kozhikode.

\section{Specimen}

Specimens such as pus aspirate, blood, cerebrospinal fluid, sputum, urine, pleural fluid, corneal scrapings and ascitic fluid received in Microbiology laboratory for culture and sensitivity.

\section{Sample Size}

A total of 100 randomly chosen non-repetitive isolates obtained from cultures of above specimens.

\section{Inclusion Criteria}

1. Specimens from patients admitted in Government Medical College, Kozhikode.

2. Gram-negative bacteria which were resistant to $1^{\text {st }}, 2^{\text {nd }}$ and 3 rd generation cephalosporins.

\section{Ethical Committee Approval}

Ethical clearance to perform the study was obtained from the Institutional Ethical Committee.

\section{Detection of AmpC}

Identification of microorganisms was performed according to standard procedures. ${ }^{10}$ Antibiotic sensitivity testing was done by Kirby-Bauer's method as per CLSI guidelines (2012). The following antibiotic discs were tested: Ceftazidime $(30 \mu \mathrm{g})$, Cefotaxime $(30 \mu \mathrm{g})$, Ceftriaxone $(30 \mu \mathrm{g})$, Cefepime $(30 \mu \mathrm{g})$, Cefoxitin $(30 \mu \mathrm{g})$, Ampicillin $(10 \mu \mathrm{g})$, Gentamicin $(10 \mu \mathrm{g})$, Amikacin $(30 \mu \mathrm{g})$, Ciprofloxacin $(5 \mu \mathrm{g})$ and Meropenem (10 $\mu \mathrm{g}$ ) [HiMedia laboratories, Mumbai, India]. The isolates found resistant to cefoxitin (zone size $\leq 14 \mathrm{~mm}$ ) were considered as potential AmpC $\beta$-lactamase producers and were further tested with combined disc diffusion test. 11

\section{Phenotypic Detection Method for Detection of AmpC Enzymes}

Combined disc diffusion test using Phenyl boronic acid (PB): The differences in inhibition zones for cefoxitin $(30 \mu \mathrm{g})$ discs alone and in combination with $400 \mu \mathrm{g}$ of phenylboronic acid (PB) $120 \mathrm{mg}$ dissolved in $3 \mathrm{~mL}$ dimethyl sulfonic acid $+3 \mathrm{~mL}$ distilled water) [HiMedia laboratories, Mumbai, India] were determined. An increase of $>5 \mathrm{~mm}$ in zone diameter in the presence of phenylboronic acid compared with cefoxitin tested alone was considered to be positive for the presence of AmpC $\beta$-lactamase.11 (Figure 1).

\section{Control Strains used in all Methods}

Negative control ATCC E.coli 25922 and positive control Klebsiella pneumoniae 700603.12

\section{ESBL Detection was done on the AmpC Positive Isolates by E-test Strips}

E-Test for ESBLs: E-test strips (bioMerieux) were applied on to MHA with the MIC scale facing upwards. One end of strip contains a gradient of Ceftazidime (TZ) (MIC test range of 0.5 to $32 \mu \mathrm{g} / \mathrm{mL}$ ) and the other end with a gradient of Ceftazidime plus a constant concentration of clavulanate (TZL) $(4 \mu \mathrm{g} / \mathrm{mL})$. The presence of ESBL is confirmed by the appearance of a phantom zone or deformation of the TZ ellipse or when either the MIC of TZ is reduced by $\geq 3 \log _{2}$ dilutions in the presence of clavulanic acid (Figure 2, 3).

\section{RESULTS}

As per the criteria, 100 Gram-negative bacteria which were resistant to cefotaxime, ceftazidime and ceftriaxone obtained from various clinical specimens were tested for the presence of AmpC. E-test for the detection of ESBL was done on AmpC positive isolates. Majority of patients were male. Females constituted $46 \%$ and males $54 \%$. Patients in the age group of 1 month to 90 years were included in this study. Most of the cases were in the elderly age group of $>50$ years $(47 \%)$ 
Twenty five percent belonged to age group of 13-49 years (Table 1).

The antimicrobial susceptibility pattern of 100 Gramnegative isolates is summarised in Table 2. Among the 100 study isolates, $48(48 \%)$ were found to be cefoxitin resistant (Graph 1). Of the 48 cefoxitin resistant isolates, 24 (24\%) were found as AmpC producers (Graph 1). Among the 24 AmpC positive isolates, majority 8 (33\%) were isolated from blood. AmpC-positive organisms were also isolated from pus, urine, sputum, CSF and ascitic fluid (table 3). Among the 24 AmpC-positive isolates, E. coli comprises the majority 10 (41.6\%). The percentage distribution of AmpC production in different Gram-negative isolates is given in Graph 2.

Of the 24 AmpC positive isolates, 13 (54\%) were ESBL positive by E-test. E. coli, Enterobacter spp. and Klebsiella spp. were isolated, of which E. coli (54\%) were in majority. The remaining 11 were pure AmpC producers (Graph 3). Among the 13 ESBL/AmpC co-carriage isolates, 12 (92.3\%) were resistant to cefepime. Nine of 11 (81.8\%) pure AmpC isolates were also cefepime resistant. Among the $24 \mathrm{AmpC}$ positive isolates, only 7 (29\%) isolates showed resistance to meropenem.

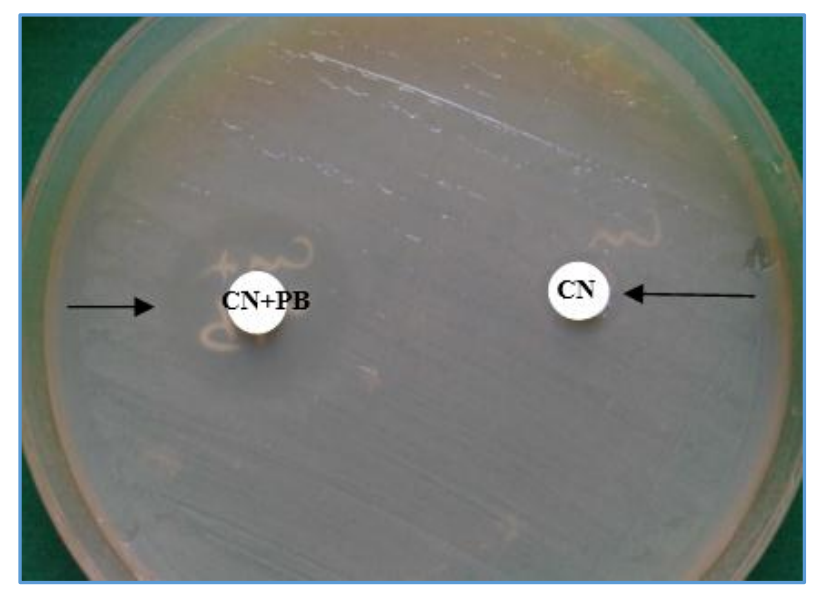

Figure 1. Combined Disc Diffusion for AmpC Detection. Test Organism showing $>5 \mathrm{~mm}$ Increase in Zone Diameter in the Presence of Phenylboronic Acid (CN-Cefoxitin: 6 mm, CN+PB-Cefoxitin+ Phenylboronic Acid: $12 \mathrm{~mm}$ ).

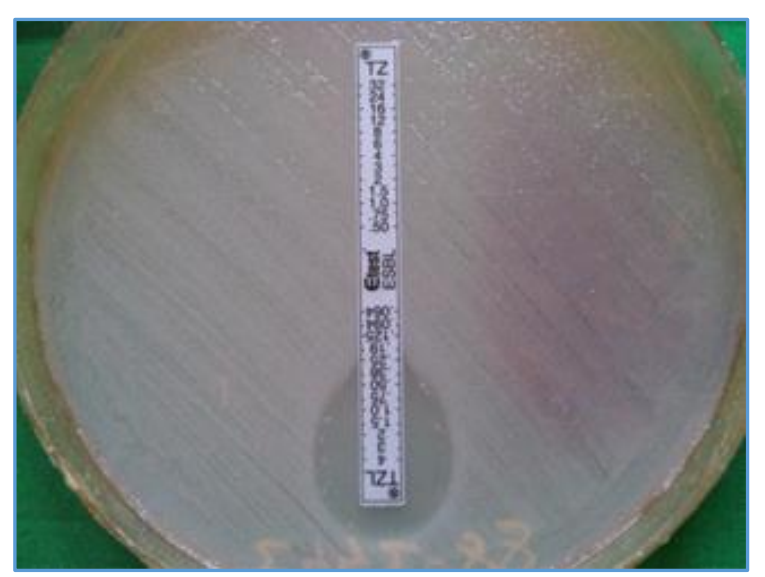

Figure 2. E-Test for the Detection of ESBL: MIC of TZ is Reduced by $\geq 3 \log _{2}$ dilutions in the Presence of Clavulanic Acid (MIC of TZ-Ceftazidime: 32, MIC of TZL Ceftazidime+Clavulanate: 0.25 )

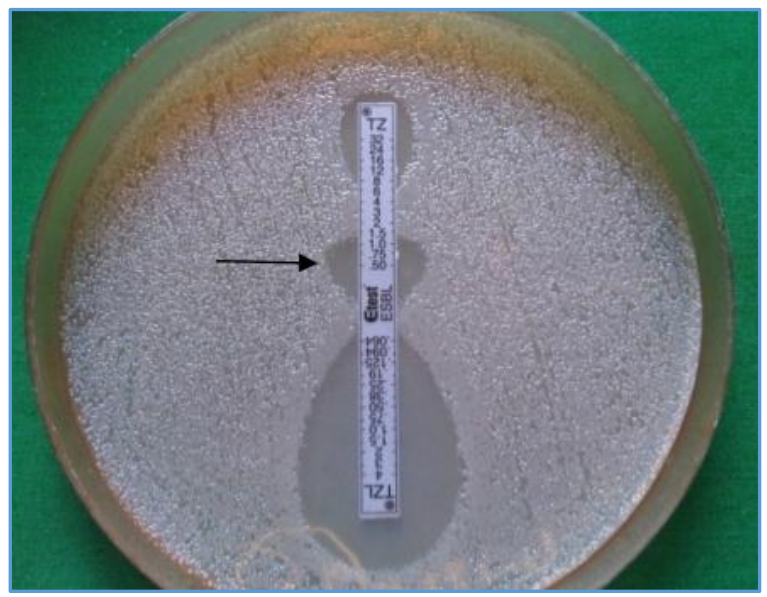

Figure 3. E-Test - Phantom Zone Indicative of ESBL

\begin{tabular}{|c|c|c|}
\hline Age & Number & Percentage \\
\hline$<1$ yr. & 18 & 18 \\
\hline $1-12$ yrs. & 10 & 10 \\
\hline $13-49$ yrs. & 25 & 25 \\
\hline$>50$ yrs. & 47 & 47 \\
\hline Table 1. Distribution of Cases According to Age \\
\hline
\end{tabular}

\begin{tabular}{|c|c|c|}
\hline $\begin{array}{c}\text { Antimicrobial } \\
\text { Agent }\end{array}$ & $\begin{array}{c}\text { Total No. } \\
\text { Resistant }\end{array}$ & Percentage \\
\hline Ampicillin $(10 \mu \mathrm{g})$ & 100 & 100 \\
\hline Cefoxitin $(30 \mu \mathrm{g})$ & 48 & 48 \\
\hline Ceftriaxone $(30 \mu \mathrm{g})$ & 100 & 100 \\
\hline Cefotaxime $(30 \mu \mathrm{g})$ & 100 & 100 \\
\hline Ceftazidime $(30 \mu \mathrm{g})$ & 100 & 100 \\
\hline Cefepime $(30 \mu \mathrm{g})$ & 91 & 91 \\
\hline Gentamicin $(10 \mu \mathrm{g})$ & 68 & 68 \\
\hline Amikacin $(30 \mu \mathrm{g})$ & 29 & 29 \\
\hline Ciprofloxacin $(5 \mu \mathrm{g})$ & 56 & 56 \\
\hline Meropenem $(10 \mu \mathrm{g})$ & 24 & 24 \\
\hline Table 2. Antibiotic Susceptibility Pattern of 100 Gram- \\
negative Isolates \\
\hline
\end{tabular}

\begin{tabular}{|c|c|c|}
\hline Specimen & Total Number & AmpC Positive (\%) \\
\hline Blood & 39 & $8(33 \%)$ \\
\hline Pus & 16 & $6(25 \%)$ \\
\hline Urine & 22 & $4(16 \%)$ \\
\hline Sputum & 15 & $3(12 \%)$ \\
\hline CSF & 5 & $2(8 \%)$ \\
\hline Ascitic fluid & 1 & $1(4 \%)$ \\
\hline Corneal scraping & 1 & 0 \\
\hline Pleural fluid & 1 & 0 \\
\hline Total & 100 & $\mathbf{2 4}(\mathbf{2 4 \% )}$ \\
\hline \multicolumn{3}{|c|}{ Table 3. AmpC Production in Isolates from } \\
\hline
\end{tabular}

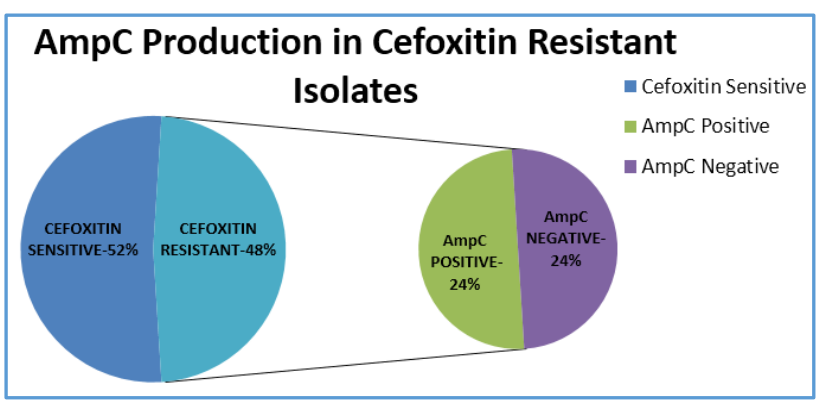

Graph 1. AmpC Production in Cefoxitin-Resistant Isolates 


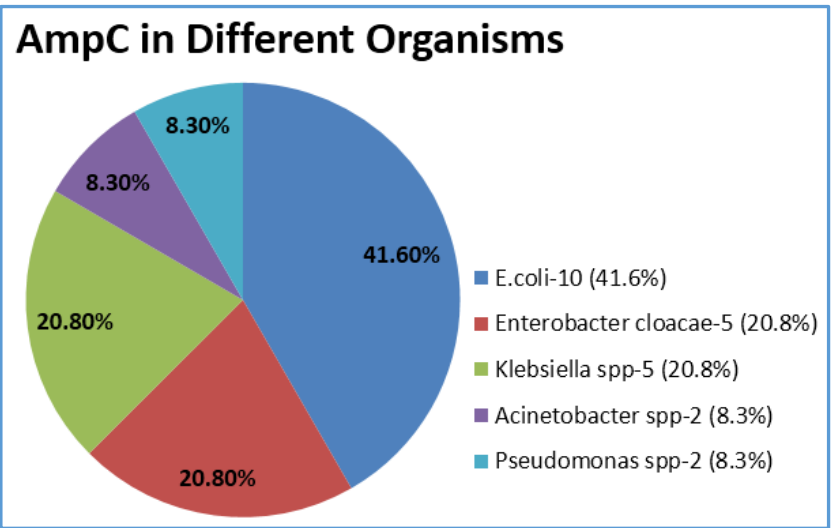

Graph 2. AmpC Detection in Different Organisms

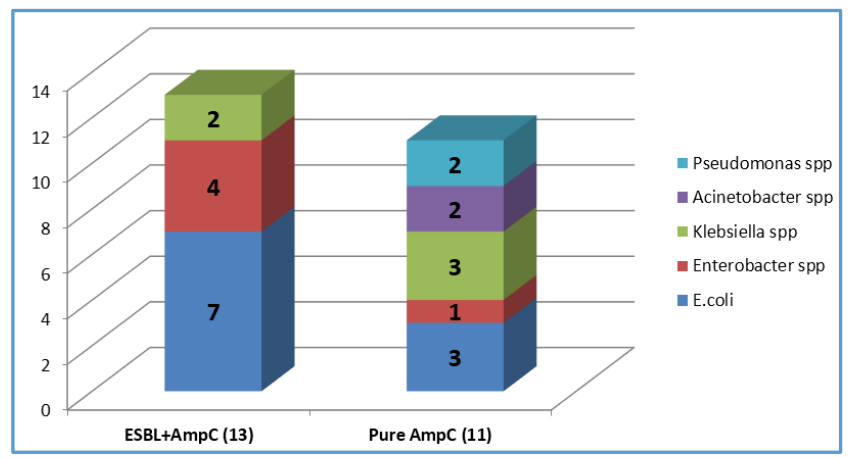

Graph 3. ESBL Positives in AmpC Producers

\section{DISCUSSION}

Cephalosporins are the first-line drugs used in the treatment of infections caused by members of family Enterobacteriaceae. Their extensive use has led to increased prevalence of plasmid-mediated AmpC among these organisms. AmpC $\beta$-lactamase production is determined by genes commonly found on the chromosomes of members of the family Enterobacteriaceae like Enterobacter spp., Shigella spp., Providencia spp., Citrobacter freundii, Morganella morganii, Serratia marcescens and Escherichia coli. Plasmidmediated AmpC $\beta$-lactamases are acquired by the transfer of chromosomal genes for the inducible AmpC $\beta$-lactamase and are seen in isolates of E. coli, Klebsiella pneumoniae, Salmonella spp., Citrobacter freundii, Enterobacter aerogenes and Proteus mirabilis. 13

In the present study, among 100 Gram-negative isolates, $48(48 \%)$ were resistant to cefoxitin by disc diffusion method. Of these 48 Cefoxitin-resistant isolates, 24 (24\%) were AmpC producers by combined disc diffusion test using phenyl boronic acid as inhibitor (IBM). Cefoxitin resistance in the remaining 24 isolates that did not show any enhancement with the addition of BA may be due to mechanisms other than AmpC such as porin channel mutation. ${ }^{14}$ The Cefoxitin-BA method cannot differentiate between plasmid-mediated AmpC, iAmpC or derepressed AmpC enzymes.

The prevalence of plasmid-mediated AmpC varies widely in different parts of the world ranging from $2 \%$ to $46 \%{ }^{6}$ In India, the prevalence ranges from $8 \%$ to $47 \% .15$ In the present study, the occurrence of AmpC $\beta$-lactamases was found in $24 \%$ of the isolates. Other studies have shown AmpC occurrence varying from $14.8 \%-52.1 \%{ }^{16}$

In the present study, among the 24 AmpC positive isolates, ESBL and AmpC co-existed in 13 (13\%) isolates. The remaining 11 were pure AmpC producers. Similar results
(19\% ESBL AmpC co-carriage) were obtained by Vijay Shivanna and Achut Rao. ${ }^{16}$ ESBL detection was done by an inhibitor-based method (Ceftazidime and Ceftazidime+Clavulanate) using E-test in our study. The inhibitor-based confirmatory tests are most appropriate for isolates not co-producing an inhibitor-resistant $\beta$-lactamase like AmpC, since high level production of AmpC may prevent the detection of ESBL. Moreover, in these organisms, clavulanic acid may act as an inducer of high level AmpC production resulting in false negative result in ESBL confirmatory test. Tazobactam and sulbactam are much less likely to induce AmpC $\beta$-lactamases and are therefore, preferable inhibitors for ESBL detection tests in AmpC coproducers. Another approach is to include cefepime as an indicator drug. High level AmpC production has a minimal effect on the activity of cefepime, making this drug a more reliable detection agent for ESBLs in the presence of AmpC. 17

In this study, of the $24 \mathrm{AmpC}$ positive isolates, 10 (41.6\%) were E. coli, 5 (20.8\%) were Enterobacter cloacae, 5 (20.8\%) were Klebsiella pneumoniae, 2 (8.3\%) were Acinetobacter baumannii and 2 (8.3\%) were Pseudomonas aeruginosa. Although reported with increasing frequency, the true rate of occurrence of AmpC $\beta$-lactamases in different organisms including members of Enterobacteriaceae remains unknown. In India, AmpC prevalence has been reported in Klebsiella spp. (24.1\%) and E. coli (37.5\%). In a study by Hemalatha et al, they have reported $8 \%$ detection of AmpC $\beta$-lactamases production in E. coli and Klebsiella spp. by inhibitor-based method. ${ }^{15}$

AmpC enzymes primarily confer resistance to penicillins, oxyimino-beta-lactams and cephamycins with reduced affinity for cefepime and cefpirome. ${ }^{18}$ Contrary to the above statement, in this study, a higher rate of cefepime resistance in both AmpC isolates and ESBL/AmpC co-carriage isolates were observed. Among the 11 pure AmpC producers, 9 (81.8\%) were resistant to cefepime. In ESBL/AmpC cocarriage isolates, 12 of $13(92.3 \%)$ were also cefepime resistant. Cefepime resistance has been reported in a study by Jose M. Rodríguez-Martínez ${ }^{19}$ in a clinical isolate of Enterobacter aerogenes. In recent years, rare AmpC-type $\beta$ lactamases that confer resistance to cefepime and cefpirome have been recovered from E. coli, Serratia marcescens and Enterobacter cloacae.20,21,22

\section{CONCLUSION}

The boronic acid disk test is a practical and efficient method based on the current CLSI methodology to detect plasmidmediated AmpC $\beta$-lactamases in organisms that usually do not harbour genes for these enzymes. Studies have shown that patients with bloodstream infections with these organisms and treated with expanded-spectrum cephalosporins had poor clinical outcome. AmpC $\beta$-lactamase production is frequently accompanied by multidrug resistance. Meropenem is superior to other antibiotics for the treatment of serious infections due to AmpC $\beta$-lactamaseproducing Gram-negative bacteria.

\section{REFERENCES}

[1] Coudron PE, Moland ES, Thomson KS. Occurrence and detection of AmpC $\beta$-lactamases among Escherichia coli, Klebsiella pneumoniae and Proteus mirabilis isolates at a veterans medical center. J Clin Microbiol 2000;38(5):1791-6. 
[2] Bush K, Jacoby GA, Medeiros AA. A functional classification scheme for $\beta$-lactamases and its correlation with molecular structure. Antimicrob Agents Chemother 1995;39(6):1211-33.

[3] Drawz SM, Bonomo RA. Three decades of betalactamase inhibitors. Clin Microbiol Rev 2010;23(1):160-201.

[4] Philippon A, Arlet G, Jacoby GA. Plasmid-determined AmpC-type $\quad \beta$-lactamases. Antimicrob Agents Chemother 2002;46(1):1-11.

[5] Thomson KS. Extended-spectrum-beta-lactamase, $A m p C$ and Carbapenemase issues. J Clin Microbiol 2010;48(4):1019-25.

[6] Jacoby GA. AmpC beta-lactamases. Clin Microbiol Rev 2009;22(1):161-82.

[7] Tondi D, Calò S, Shoichet BK, et al. Structural study of phenyl boronic acid derivatives as AmpC $\beta$-lactamase inhibitors. Bioorg Med Chem Lett 2010;20(11):34169.

[8] Yagi T, Wachino J, Kurokawa H, et al. Practical methods using Boronic acid compounds for identification of class $\mathrm{C}$ beta-lactamase producing Klebsiella pneumoniae and Escherichia coli. J Clin Microbiol 2005;43(6):2551-8.

[9] Song W, Bae IIK, Lee YN, et al. Detection of extendedspectrum beta-lactamases by using Boronic acid as an AmpC beta-lactamase inhibitor in clinical isolates of Klebsiella spp. and Escherichia coli. J Clin Microbiol 2007;45(4):1180-4.

[10] Paterson DL, Bonomo RA. Extended Spectrum Betalactamases: a clinical update. Clin Microbiol Rev 2005;18(4):657-86.

[11] Manoharan A, Sugumar M, Kumar A, et al. Phenotypic \& molecular characterization of AmpC $\beta$-lactamases among Escherichia coli, Klebsiella spp. \& Enterobacter spp. from five Indian Medical Centres. Indian J Med Res 2012;135(3):359-64.

[12] Clinical and Laboratory Standards Institute. Performance standards for antimicrobial susceptibility testing, 20th informational supplement. CLSI M100-S20. Clinical and Laboratory Standards Institute, Wayne, PA. 2010.
[13] Medeiros A. An evolution and dissemination of $\beta$ lactamases, accelerated by generations of $\beta$-lactam antibiotics. Clin Infect Dis 1997;24(1):19-45.

[14] Ananthan S, Subha A. Cefoxitin resistance mediated by loss of a porin in clinical strains of Klebsiella pneumoniae and Escherichia coli. Indian J Med Microbiol 2005;23(1):20-3.

[15] Hemalatha V, Padma M, Sekar U, et al. Detection of AmpC $\beta$-lactamases production in Escherichia coli and Klebsiella by an inhibitor based method. Indian J Med Res 2007;126(3):220-3.

[16] Shivanna V, Rao A. Detection of co-existence of $\beta$ lactamases in Gram negative bacteria using disc potentiation tests. Indian $J$ Microbiol Res 2017;4(1):64-7.

[17] Khan MKR, Thukral SS, Gaind R. Evaluation of a modified double-disc synergy test for detection of extended spectrum $\beta$-lactamases in AmpC $\beta$ lactamase producing Proteus mirabilis. Indian J Med Microbiol 2008;26(1):58-61.

[18] Gupta V. An update on newer $\beta$-lactamases. Indian J Med Res 2007;126(5):417-27.

[19] Rodríguez-Martínez JM, Fernández-Echauri $P$, Fernández-Cuenca F, et al. Genetic characterization of an extended-spectrum AmpC cephalosporinase with hydrolysing activity against fourth-generation cephalosporins in a clinical isolate of Enterobacter aerogenes selected in vivo. J Antimicrob Chemother 2012;67(1):64-8.

[20] Mammeri H, Nazic H, Naas T, et al. AmpC $\beta$-lactamase in an Escherichia coli clinical isolate confers resistance to expanded-spectrum cephalosporins. Antimicrob Agents Chemother 2004;48(10):4050-3.

[21] Mammeri HL, Poirel L, Bemer P, et al. Resistance to cefepime and cefpirome due to a 4-amino-acid deletion in the chromosome-encoded AmpC $\beta$ lactamase of a Serratia marcescens clinical isolate. Antimicrob Agents Chemother 2004;48(3):716-20.

[22] Barnaud G, Labia R, Raskine L, et al. Extension of resistance to cefepime and cefpirome associated to a six amino acid deletion in the $\mathrm{H}-10$ helix of the cephalosporinase of an Enterobacter cloacae clinical isolate. FEMS Microbiol Lett 2001;195(2):185-90. 